\title{
Gastronomic Vocabulary as a Feature of Nigerian English
}

\author{
Anna A. Borisova and Yulia N. Ebzeeva \\ RUDN University \\ 10-2 Miklukho-Maklaya str., Moscow, 117198, Russia
}

\begin{abstract}
The World Englishes Paradigm studies various aspects of the English language characterized by specific peculiarities and changing as a result of contacts with indigenous languages and cultures. The history of English in Nigeria embraces 500 years of an interaction between highly different cultural systems and civilizations. Language contacts between English and the indigenous languages of Nigeria have led to its linguistic, cultural and intrastructural diversity. The aim of this article is to analyse the gastronomic vocabulary of Nigerian English influenced by the Nigerian worldview and culture. The research is focused on borrowings from African languages (mainly Yoruba and Igbo) that play a vital role in forming the culturally important lexicon of Nigerian English. The sources of the research material are dictionaries, as well as books by Nigerian writers composed in English. The analysis carried out in the course of the research allowed us to discover secondary nominations that denote Nigerian flora and cuisine, to reveal their metaphorical usage and to study corresponding figurative comparisons, idioms, proverbs and sayings. The investigation of gastronomic symbols in Nigerian speech shows universal processes of employing common gastronomic lexical units from real-life discourse as a basis for symbolization. The results of the study show that the gastronomic vocabulary and the images it creates constitute one of the most impressive Nigerian cultural codes. The knowledge of this vocabulary is instrumental in understanding those codes.
\end{abstract}

Keywords: Nigerian English, linguistic worldview, gastronomic vocabulary, floral symbols

\section{For citation:}

Borisova, Anna. A., Ebzeeva, Yulia N. (2019). Gastronomic Vocabulary as a Feature of Nigerian English. Russian Journal of Linguistics, 23 (3), 820 -836. doi: 10.22363/2312-9182-2019-23-3-820-836.

\section{Гастрономическая лексика как одна из особенностей нигерийского варианта английского языка}

\author{
А.А. Борисова, Ю.Н. Эбзеева \\ Российский университет дружбы народов \\ Ул. Миклухо-Маклая, 10, корп. 2, Москва, Россия, 117198
}

\section{Аннотация}

Парадигма «Мир английского языка» (World Englishes Paradigm) изучает различные вариантные проявления, которые характеризуются специфическими особенностями и изменениями вследствие контактов английского языка с автохтонными языками и культурами. История английского языка 
в Нигерии охватывает 500 лет взаимодействия очень разных культурных систем и цивилизаций. Языковые контакты между английским языком и коренными языками Нигерии привели к лингвокультурному и внутриструктурному разнообразию. Целью данной статьи является анализ гастрономической лексики нигерийского варианта английского языка, которая рассматривается в контексте влияния менталитета и культуры нигерийцев на их речевую деятельность. В центре внимания заимствования из африканских языков (в основном йоруба и игбо), которые представляют собой неотъемлемый пласт культурно значимой лексики английского языка Нигерии и существенно обогащают его словарный состав. Материал для исследования извлекался из лексикографических источников, а также англоязычных художественных произведений нигерийских авторов. В ходе проведенного анализа были выявлены случаи вторичной номинации лексем, обозначающих флору Нигерии и нигерийскую кухню, их метафорическое употребление, а также их использование в сравнительных оборотах, фразеологизмах и паремиях. Исследование гастрономической символики в речи нигерийцев позволило проследить универсальные процессы использования общеупотребительных, близких повседневной жизни гастрономических лексем в качестве основы для символизации и сделать вывод о том, что гастрономическая лексика и создаваемые с ее помощью образы составляют один из ярких культурных кодов народа. Знание этой лексики играет важную роль в понимании этих кодов.

Ключевые слова: нигерийский вариант английского языка, языковая картина мира, гастрономическая лексика, флористические символь

\section{Для цитирования:}

Борисова А.А., Эбзеева Ю.Н. Гастрономическая лексика как одна из особенностей нигерийского варианта английского языка // Russian Journal of Linguistics. 2019. Т. 23. No 3. С. 820 836. doi: 10.22363/2312-9182-2019-23-3-820-836.

\section{1. Введение}

Распространение английского языка на все континенты, в том числе на африканский, привело к появлению ряда вариантов английского языка, «отличающихся друг от друга тем, что в каждом из них проецировалась культура их пользователей, и нередко в формирующиеся варианты переносились черты родных языков пользователей» (Прошина 2017:7). Первые научные изыскания в области контактной вариантологии английского языка, объединившей социолингвистов, лингвокультурологов и литературоведов, появились в 1950-1960-е гг. в трудах британского лингвиста Д.Р. Фирта, который утверждал, что английский язык «международный не только в Европе, но и в Азии и Африке и служит образу жизни африканских народов...» (Firth 1956/2006: 204). В это же время появились труды известного лингвиста Б. Качру, который изучал индийский вариант английского языка, а также работа отечественных ученых Т.М. Беляевой и И.А. Потаповой «Английский язык за пределами Англии» (1961), изучавшими функционирование английского языка за пределами проживания англосаксов. Тем не менее, данная парадигма до сих пор не получила большого распространения в отечественной науке. В 2017 г. была опубликована монография известного российского лингвиста 3.Г. Прошиной «Контактная вариантология английского языка. Проблемы теории», рассматривающая основополагающие и дискуссионные проблемы новой лингво-методической парадигмы, связанной с глобальным распространением английского языка в мире и его диверсификацией. Данная парадигма, известная как World Englishes Paradigm, сосредоточена на вариантных проявлениях языка, который характеризуется специфическими особенностями 
и претерпевает изменения в результате взаимодействия с автохтонными языками и влияния автохтонной культуры. Следует отметить, что в последние годы нигерийские ученые также проявляют все больший интерес к изучению особенностей английского языка в Нигерии (Igboanusi 2002, Bamgbose 1998, Banjo 1995).

Важным достижением лингвистики на современном этапе является то, что «...язык уже не рассматривается «в самом себе и для себя»; он предстает в новой парадигме с позиции его участия в познавательной деятельности человека» (Маслова 2017: 4). Современная антропоцентрическая парадигма существенно раздвигает рамки лингвистических исследований, которые сфокусированы на деятельностной природе языка и его участии в процессе жизнедеятельности человека и социума, и объединила усилия представителей различных дисциплин, изучающих человека, на вопросах взаимодействия языка, менталитета, культуры, языкового сознания и языковой картины мира.

Лингвисты активно занимаются изучением того, каким образом знания человека о мире, фоновые знания структурируются в языке в процессе языковой коммуникации (Арутюнова 1999, Богданова 2017, Карасик 2009, 2016; Gladkova \& Larina 2018a, b; Goddard \& Wierzbicka 2014, Kecskes 2014, Larina et al. 2017; Schnurr \& Zayts 2017, Wierzbicka 2003, 2006 и многие др.). Язык воплощает культуру его носителей, предоставляя говорящему средства для выражения актуальных понятий и отношений. Процессы категоризации непосредственно связаны с человеком, его представлениями о мире и особенностями его восприятия. Носитель языка характеризует окружающий его мир при помощи особых языковых символов, которые образуют код культуры, специфичный для каждой национальной культуры. В процессах категоризации мира проявляются коды культуры, которые реализуются в языке.

Большое внимание уделяется проблеме отражения картины мира в языке, в рамках которой разрабатывается производное понятие «языковая картина мира», которая, по определению Н.Ф. Алефиренко, в конечном итоге есть «воспроизведение в языке при помощи средств языка предметов и явлений окружающей действительности» (Алефиренко 2016: 134). И.В. Зыкова отмечает, что «полным вариантом обозначения картины мира принято считать такое обозначение, как «концептуальная картина мира», которая характеризуется как «сложное концептуальное явление (образование), неотъемлемо связанное с человеческим познанием окружающей действительности и знанием о ней, их (т.е. познания и знания) границ и глубины (Зыкова 2015: 24).

На современном этапе исследования языка лингвокультурология изучает особое культурное пространство - коды культуры. Образы пищевых продуктов и всего, что с ними связано, составляют один из самых богатых и разветвленных культурных кодов любого народа (Маслова, Пименова 2016: 87). Разнообразные виды пищевых продуктов, традиции приготовления блюд, связанные с ними праздники и ритуалы имеют непосредственное отношение к основной системе ценностей народа.

В нашей статье мы основываемся на том, что современные варианты английского языка - это явления как лингвистические, так и культурно-мировоз- 
зренческие и лингвокультурологические. Они отражают культуру и менталитет народов и имеют следы переноса некоторых черт родного языка и родной культуры, что необходимо для сохранения их лингвокультурной идентичности.

Нигерийский вариант английского языка, как и другие его варианты, хранит ценности культуры, отношения и символы, которые запечатлены прежде всего в его лексике и фразеологии. Целью данного исследования является рассмотрение лингвокультурологического своеобразия нигерийского варианта английского языка на примере гастрономической лексики в контексте влияния менталитета и культуры нигерийцев на их речевую деятельность. Главная задача нашей работы - интерпретация нигерийского культурного пространства на примере гастрономической лексики, установление взаимосвязи своеобразия нигерийского варианта английского языка с менталитетом и фрагментами языковой картины мира нигерийцев.

Материал извлекался из лексикографических источников (A Dictionary of Nigerian English Usage, H. Igboanusi; Igbo-English Dictionary, M. Echeruo; YorubaEnglish/English-Yoruba Dictionary and Phrasebook, C. Oyeleke, A. Mawadza), а также англоязычных художественных произведений нигерийских авторов (Ch. Achebe, Ch.N. Adichie, S. Atta, F. Nwapa, I. Okoye and L. Shoneyin).

Было проанализировано 9 произведений шести англоязычных нигерийских писателей общим объемом 2500 страниц, из которых рассмотрено более 100 репрезентативных примеров.

\section{2. Языковая и социокультурная ситуация в Нигерии}

Английский язык в Нигерии является результатом тесного взаимодействия на протяжении почти 500 лет принципиально отличных культурных систем и цивилизаций. В период колониального господства британцы принесли в страну английский язык, христианство и элементы англосаксонской культуры. Нигерия является самой полиэтнической страной в Африке к югу от Сахары, где английский является официальным языком в рамках федеральной конституции и служит образу жизни нигерийцев. Нигерия относится к одной из крупнейших англоговорящих и многоязычных стран. В ней насчитывается более 250 этнических групп, представители которых говорят на 521 языке. Около 70\% населения приходится на три народа: игбо, йоруба и хауса. В результате английский язык взаимодействует с нигерийскими автохтонными языками, в первую очередь игбо, йоруба, хауса. Языковые контакты английского языка, языка бывшей метрополии, и местных языков Нигерии привели к лингвокультурологическому и внутриструктурному своеобразию.

В силу особенностей природной среды обитания народа, его основного исторического рода занятий (охота - рыболовство - скотоводство - земледелие), его культурно-исторического развития национальная кухня является одной из самых специфичных областей бытования народа, что, конечно, отражается на ее лингвистическом обеспечении (на системе наименований, относящихся к пищевому сырью, полуфабрикатам, готовым блюдам и рецептуре их изготовления, а также на символике этих наименований) (Маслова, Пименова 2016: 29). 
Национальная кухня Нигерии является органичной частью западноафриканской кухни и отчасти всей Субтропической Африки, которую отличают специфические способы приготовления и потребления пищи, что получает отражение в языке. Культурологически представляет интерес пример, где известная нигерийская писательница Чимаманда Нгози Адичи перечисляет гастрономические пристрастия нигерийцев, всеядность своих соотечественников, создавая образ этнокультурной идентичности нигерийцев:

Nigeria is a nation of people who eat beef and chicken and cow skin and intestines and dried fish in a single bowl of soup, and it is called assorted (Нигерия - это начия людей, которые едят говядину, курииу, коровью кожу и кишки, и сушеную рыбу в одной тарелке супа, и этот суп называется «ассорти».) (Americanah, 2013: 421).

Национальная кухня нигерийцев, ее отражение в языке, является фрагментом картины мира африканских народов. Богатство флоры и фауны, климат Тропической Африки влияют на традиции национальной кухни, на способы приготовления блюд. Для понимания своеобразия нигерийской кухни необходимо принимать во внимание этнокультурную неоднородность нигерийцев. Блюда национальной кухни Нигерии традиционно подразделяют на южные и северные, что связано с различными ингредиентами, входящими в их состав. На юге страны традиционными продовольственными культурами, получившими наибольшее распространение, являются ямс и маниок. В северных штатах главные продовольственные культуры - просо и сорго, которые дают достаточно устойчивые урожаи при недостатке влаги. Здесь выращивают бобовые, кукурузу, рис, томаты, овощи. Из плодов масличной пальмы и арахиса получают растительные жиры.

По оценкам нигерийского лингвиста Г. Игбоануси, некоторые гастрономические термины, распространенные в нигерийском варианте английского языка, встречаются в других англоязычных странах Западной Африки, таких как Гана, Камерун, Сьерра Леоне: foo-foo/fufu - (йоруба) блюдо из кассавы; egusi soup (йоруба) - суп из семян дыни; suya - (хауса) запеченное мясо со специями (Igboanusi 2002: 22). Это свидетельствует о единстве западноафриканского гастрономического тезауруса и об обогащении западноафриканских вариантов английского языка заимствованиями из автохтонных языков Нигерии.

Изобилие культурно-специфичных наименований национальной кухни в английский вариант английского языка часто делает его трудным для понимания. Наглядный пример, свидетельствующий о необходимости знания реалий из сферы гастрономии Нигерии для успешной коммуникации находим в работе нигерийского исследователя Т. Аджани, который приводит разговор в ресторане между официантом и посетителем:

Bola: What do you have on the menu today?

Waiter: We have dodo, akara, amala, eba and tuwo.

Bola: What about soup, what kind of soup do you have for today?

Waiter: We have egusi soup, ewedu and ogbono. Which one would you prefer? We also have bush meat, obokun, oku-Eko and ponmo.

Bola: Okay, give me a plate of amala, egusi soup and bush meat... How much will that be? Waiter: twenty naira and fifty kobo. 
Бола: Что у Вас сегодня в меню?

Официант: У нас есть додо, амала, эба и туво.

Бола: А что насчет супа, какой у Вас сегодня есть суп?

Официант: У нас есть суп эгуси, эведу и оногбо. Какой Вы предпочтете? У нас также есть дикое мясо, обокун, оку-эко и понмо.

Бола: Хорошо, принесите мне тарелку амалы, эгуси суп и дикое мясо. Сколько это будет стоить?

Официант: двадцать найр и пятьдесят кобо (Ajani 2007).

В этом примере мы видим много наименований нигерийской кухни, которые заимствованы из трех основных нигерийских языков. Dodo (жареный плантен), akara (блюдо из коровьего гороха), amala (блюдо из ямса), eba (блюдо из клубней кассавы), egusi (суп из дыни), ewedu (соус из листьев растений), obokun, oku-eko u ропто являются заимствованиями из йоруба. Tuwo - это популярная еда у хауса, в то время как ogbona - это суп, популярный у игбо. Данный фрагмент подтверждает, что «каждая этнокультура до сих пор в значительной мере является «вещью в себе», малопонятной для носителей иных (особенно генетически и типологически удаленных) культур и языков» (Маслова, Пименова 2016: 28-29).

В художественном тексте находим интересный лингвокультурологический пример, свидетельствующий о важности приема пищи в нигерийской культуре и скрытом подтексте, понять который можно только при наличии знаний культурного фона:

What he took back to Harrison were the compliments from the guests about how pretty everything was, but he did not add that the guests then bypassed his canapés to eat Ugwu's pepper soup and moi-moi and chicken boiled in bitter herbs. - Он передал Харрисону комплименты от гостей о том, как все было хорошо, но он не упомянул, что гости не стали есть его канапе, потому что ели приготовленный Углу перечный суп, мой-мой и тушенную в горьких травах курицу (Adichie 2006:109).

\section{3. Флористические символы Нигерии: yams и kola nuts}

Многие растения издавна служат основой питания народов Нигерии и входят в рецептуру многих блюд национальной нигерийской кухни, что, соответственно, находит отражение в языке. В рационе питания африканцев основным элементом исторически являлись зерновые и ямс. Широкое распространение флористического символа yams (ямс) в произведениях нигерийский авторов позволяет считать его одним из ключевых в нигерийской культуре и в языковой картине мира нигерийцев. В лексеме yams для африканцев воплощена культурно значимая информация: ямс является наиболее типичным растением в Нигерии, одним из основных продуктов питания, из которого готовят традиционные блюда.

Будучи одним из главных продуктов питания в Нигерии, ямс ассоциируется с различными ритуалами и празднествами. После окончания уборки урожая отмечается праздник молодого ямса — ahiajoku или new yam festival, названный по имени бога ямса у народности игбо, когда исполняются ритуальные танцы и дегустируются блюда, приготовленные из молодого ямса. Перед употреблением собранного урожая ямса необходимо принести его в дар богам. Таким образом, жители деревень благодарят своих предков и богов за благословение земли и плодородие. 
Проведенный нами анализ лексикографического материала, а также этноспецифических текстов свидетельствует о том, что название этого растения достаточно широко используется в речи нигерийцев как основание для образования переносных значений и закрепляется в составе фразеологизмов и паремиологии. Лексему yam (ямс) находим в нигерийских пословицах и поговорках:

A child's fingers are not scolded by a piece of hot yam which its mother puts into its palm. - Пальцы ребенка никогда не обожжет кусок горячего ямса, который его мать кладет ему в руку (Мать плохо не сделает) (Achebe 1958: 63).

Ярким свидетельством важности данного растения в жизни нигерийцев, являющегося традиционным ежедневным продуктом питания, представляется следующий пример из произведения нигерийской писательницы Л. Шонейин, который является образцом языкового творчества носителя нигерийского английского языка:

(1) Whether we accompany our palm oil with yam or we accompany our yam with palm oil, the most important thing is to have a good meal of oil-soaked yam. We must help each other. - Едим ли мы ямс с пальмовым маслом, или пальмовое масло с ямсом, самое главное - съесть вкусное блюдо из ямса в масле. Мы должны помогать друг другу (Shoneyin 2010: 100).

Лексема yam (ямс) часто используется в сравнительных оборотах при положительных оценках качеств, свойств, умений. Следующие компаративные обороты характерны для определенного семиотического пространства и являются национально-специфичными:

(2) For, our fathers said that old friends are like the heads of yams that grow and don't die. - Наши отцы говорили, что старые друзья как головы ямса, растут и не умирают (Nwapa 1966:163);

(3) He grew rapidly like a yam tendril in the rainy season. - Он вырос быстро, как побег ямса в сезон дождей (Achebe 1958: 52);

(4) It (her English) reminded him of a slicing a yam with a newly sharpened knife, the easy perfection in every slice. - Ее английский был подобен тому, как режут ямс наточенным ножом, легкость и совершенство в каждом кусочке (Adichie 2006: 22).

Эти красочные сравнения (2-4) передают национально-культурные особенности мировидения и уникальный колорит языка, являясь ярким вербальным средством выражения особенностей нигерийской культуры.

В нашем материале встретилось метафорическое употребление лексемы yams, что представляется важным фактом, так как, по справедливому замечанию А.П. Чудинова, «метафора относится к числу тех феноменов, в которых наиболее ярко проявляется «душа народа», его ментальный мир» (Чудинов 2004: 29). В следующем примере (5) нигерийская писательница Флора Нвапа использует красочную метафору, сравнивая луну с кусочком ямса, которого хватает, чтобы осветить весь мир:

(5) «What a bright moon», Efuru remarked. «Yes, how bright it is. The wonderful work of nature. A piece of yam that is sufficient for all the world》. — «Какая яркая луна», заметила Эфуру. «Да, какая она яркая. Прекрасное творение природы. Кусочек ямса, которого хватает, чтобы осветить весь мир» (Nwapa 1966: 13). 
Приведем еще некоторые примеры вторичной номинации лексемы yam в произведениях нигерийских писателей:

(6) Leave the white people out of it. Everybody knows they always rush to any place that has cooked yams ready for them to eat. - Не впутывай сюда белых. Все знают, что они всегда спешат в любое место, где их ждет готовый ямс (Emecheta 1994: 3);

(7) ... a girl who wore a miniskirt to evening lesson even though she had fat yams on her $\operatorname{legs}$ - ...девочка, которая надела мини-юбку на вечерний урок, хотя у нее на ногах был жирный ямс (Adichie 2004: 141).

В примере (6) cooked yams приобретает значение «все готовое», в примере (7) словосочетание fat yams используется для описания внешнего вида полного человека.

Другой флористический символ нигерийской лингвокультуры — это kola nut (орех кола), являющийся с давних времен одним из знаковых элементов традиционной культуры. В жизни нигерийцев орех кола, содержащий кофеин и являющийся природным стимулятором, имеет большое значение. Его жуют для подкрепления сил, чтобы утолить голод, во время выполнения тяжелой физической работы.

Однако орехи кола играют в традиционной культуре намного более важную роль, чем пищевая добавка. У разных народов страны они являются неотъемлемой частью различных церемоний. Ни одно праздничное застолье не обходится без орехов кола. У народов юга Нигерии они являются знаком гостеприимства. Если хозяин не может предложить гостю орех колы, он должен принести извинения. У народности йоруба принято дарить орехи кола уходящему гостю, при этом имеет значение количество орехов: нечетное количество орехов означает, что хозяин не проявляет очень дружественных чувств к гостю и не хочет продолжать с ним знакомство; четное количество орехов выражает дружеское отношение хозяина. В некоторых общинах народности игбо отмечались ограничения для женщин в отношении орехов кола, когда женщинам не разрешалось культивировать растение, а также раскалывать орехи в присутствии мужчин. В традиционной культуре орех кола считался лучшим подарком, который дарил жених семье невесты. Чем больше орехов дарил жених, тем больше он выказывал свое желание вступить в брак и проявить уважение к семье невесты. Он также используется в церемонии жертвоприношений и в церемонии предсказания судьбы. Согласно обычаю, богатые нигерийцы во время традиционных праздников раздавали беднякам орехи кола, демонстрируя свою щедрость. В патриархальные времена орехи кола и пальмовое вино употреблялись земледельцами в знак завершения их коллективного труда.

Приведем пример актуализации лексемы kola из романа Ф. Нвапы, свидетельствующий о важности данного флористического символа:

(8) We shall have kola before the business. It is a pity my husband is not at home. He went to the farm. Efuru brought two big kola-nuts. They were fit only for kings. She put them before the men, with some alligator pepper. The spokesman took one kola-nut and blessed it. Then he broke it and gave the men. - Нам стоит съесть орехи кола перед тем, как приступать к делу. Очень жаль, что моего мужа нет дома. Он 
ушел на ферму. Эфуру принесла два больших ореха кола. Они были королевского размера. Она поставила их перед мужчинами вместе с крокодильим перцем. Главный мужчина за столом взял орех кола и благословил его. Затем он разбил его и дал мужчинам (Efuru 1966: 9).

Церемония ореха кола описана в романе Чинуа Ачебе «Все распадается» (1959), где можно встретить ссылку на процесс употребления ореха кола как минимум 10 раз, что подчеркивает его важную роль в традиционной культуре Нигерии. Орехами кола угощают не только в торжественных и радостных случаях, но и при выражении соболезнования, когда соседи, односельчане, родственники приходят, чтобы выразить соболезнования в связи со смертью человека. В романе Ф. Нвапы «Эфуру» находим следующий пример:

(9) Kola was brought and as they were having the kola, other sympathizers came and join them. Some greeted Efuru and sat down to have their own share of kola or palm wine. Others said a few things in praise of the dead man. - Принесли орехи кола, и пока они их ели, другие сочувствующие присоединились к ним. Некоторые поздоровались с Эфуру и сели, чтобы съесть свою порцию орехов кола и выпить пальмового вина. Другие сказали несколько слов в память о покойном (Nwapa 1966: 205).

Важно отметить, что на примере лексемы kola также прослеживаются вторичные номинации. Нигерийцы употребляют данную лексему в значении «взятка» или «подкуп». В словаре английского языка Нигерии Г. Игбоануси посвящает отдельные страницы символике этой лексемы в речи нигерийцев:

Officer, please, help me. I will give you some cola. - Офицер, пожалуйста, помогите

мне. Я дам Вам немного денег (Igboanusi 2002: 62).

Значение имени «cola» (ореха кола) уподобляется подкупу, что мотивировало соответствующее переносное значение.

\section{4. Гастрономическая символика и флористические символы в языковой картине мира нигерийцев}

Гастрономическая лексика иллюстративна для рассмотрения национальнокультурного своеобразия нигерийского варианта английского языка, языковой картины мира нигерийцев и ее отражения в развитии лексической системы. Результаты нашего исследования свидетельствуют о том, что она является яркой чертой нигерийского варианта английского языка, свидетельствующей о его лексико-семантической и лексико-фразеологической специфике.

В данной статье мы не ставим задачу подробного описания выявленной нами гастрономической лексики, вошедшей в нигерийский вариант английского языка. Ограничимся лишь некоторыми примерами, свидетельствующими об уникальности нигерийской кухни и лексики, обслуживающей данную сферу деятельности человека.

Chin-chin (чин-чин) - это популярная закуска в Западной Африке, представляющая собой сладкое, хрустящее, похожее на пончик тесто из пшеничной муки (с добавлением молока и сахара), также может готовиться из коровьего гороха (cowpea) с добавлением земляного ореха для аромата. 
Jollof rice (рис джоллоф) - одно из традиционных блюд африканской кухни Нигерии (jollof происходит от средневекового государства Джолоф). Это блюдо иногда называют benachin (беначин), что в переводе с языка волоф означает «один горшочек». Рис с мясом тушат, заправляют помидорами, луком и перцем.

$\boldsymbol{F u f u}$ (фуфу) - традиционное блюдо национальных кухонь не только Нигерии, но и народов Западной Африки в целом. Представляет собой пюре или кашу, которую обычно готовят из толченой кассавы, ямса, реже бананов, батата, маиса или риса. В качестве специй и соусов служат окра (бамия) и томатные соусы. Фуфу подается в виде шариков, которые макают в соус и едят.

Garri (гари) (в Гане - gari, а в некоторых регионах субсахарской Африки gali) - популярное в Нигерии и Западной Африке блюдо из клубней кассавы, которое может употребляться в пищу как закуска, а также готовится каша, которая у игбо называется utara, у йоруба — eba, у хауса, в северной части страны teba. Термин garri в основном употребляется в Нигерии, Камеруне, Сьерра Леоне, Бенине и Того. Данное слово входит в состав фразеологизма to pour sand into someone's garri, имеющего значение «создать кому-либо проблему».

В произведениях нигерийских англоязычных авторов нами встретились многочисленные иллюстрации употребления и приготовления различных блюд нигерийской кухни. Внимание писателей к деталям, малоизвестным европейскому читателю, способствует созданию достоверного нарратива:

(10) I watched her pound the cocoyams, dipping the pestle often into the bowl of water so the cocoyam wouldn't stick too much to it. Still, the sticky white mash clung to the pestle, to the mortar, to Aunty Ifeoma's hand. She was pleased though, because it would thicken the onugbu soup well. — Я смотрел, как она толкла таро, окуная пест в миску с водой, чтобы таро сильно не прилипал к нему. И все же, липкая белая масса прилипала к песту, к ступе, к руке тетушки Ифеомы. Тем не менее, она была довольна, потому что это сделает блюдо онугбу достаточно густым (Adichie 2004: 165-166).

(11) Lunch was fufu and soup. The fufu was smooth and fluffy, she made it well; she pounded the yam energetically, adding drops of water into the mortar, her cheeks contracting with the thump-thump-thump of the pestle На ланч был фу-фу и суn. Фу-фу был мягкий и воздушный, она хорошо приготовила его; она энергично взбила ямс, добавив немного воды в ступу, ее щеки сотрясались каждый раз, когда она толкла пестом ямс. (Adichie 2004: 11).

(12) I molded my fufu into small balls with my fingers, dipped it in the soup, making sure to scoop up fish chunks, and then brought it to my mouth. — Я слепил мелкие шарики из фу-фу, окунал их в суп, и убедившись, что я достал из тарелки мелкие кусочки рыбы, клал их в рот. (Adichie 2004: 12).

Следует отметить, что лексема soup в нигерийском английском называет не отдельное блюдо, а подливу, соус, который едят с основным блюдом, главным образом с традиционными нигерийскими кушаньями, приготовленными из корнеплодов, таких как ямс, маниок, таро. Такие соусы готовят из листьев растений, едят с мясом, рыбой или морепродуктами. В данном случае наблюдается семантическое сужение значения лексической единицы. Что касается конкретных обозна- 
чений таких супов, то они также отличаются разнообразием. Приведем лишь несколько примеров.

Egusi soup - суп из дыни egusi (эгуси), один из наиболее популярных супов в южной Нигерии, представляет собой густую овощную подливку, которая подается к отварному рису, толченому пюре из ямса, жареным бананам. Основа эгуси - семена и ломтики сухой дыни, которые жарят в пальмовом или арахисовом масле, с луком, перцем и помидорами. Их можно тушить с мясом, курицей или рыбой и подавать также с фуфу.

Akara soup (суп акара) - готовят из бобов, перца, лука, помидоров, которые толкут, а потом обжаривают.

Elele soup (элеле суп) — готовят с добавлением к этим продуктам сушеной рыбы или креветок.

Ogbono soup (огбоно суп) - популярен у народности игбо, где его готовят из семян манго.

Ofe nsala или Igbo white soup - рыбный суп, который популярен в восточной части Нигерии, имеющий также название «белый суп» из-за своего светлого цвета, ввиду отсутствия в нем пальмового масла. В самом традиционном варианте используется сом в виде целой рыбы, также он готовится из морского угря.

Pepper soup (перечный суп) (у игбо — ngwongwo) - популярное нигерийское блюдо, которое готовится из разных видов мяса, рыбы, курицы. В качестве специй в суп обычно добавляется африканский мускатный opex (ehu seeds). Существует фразеологизм to be high on pepper soup - осмелеть.

(13) His words surprised him. He had stepped out of himself. He was high on pepper soup. - Его слова удивили его. Он превзошел себя. Он осмелел (Adichie 2013: 25).

С мучными блюдами нигерийцы употребляют острые приправы. Существует множество видов перца, которые часто используются в сочетании с другими пряностями и добавляются, в том числе, в сладкие блюда и освежающие напитки. Острые приправы не только украшают пресные мучные изделия, но и являются прекрасным профилактическим средством желудочных инфекций. Среди них «крокодилий» перец (alligator pepper) - дорогая специя в Западной Африке для супов и риса, отличающаяся жгучестью; мелкие зерна перца подают в тарелочках, чтобы желающие могли попробовать его на вкус. У игбо по традиции, когда новорожденному исполняется всего несколько дней, ему дают немного крокодильего перца, чтобы ребенок, согласно поверью, не был глухонемым:

(14) When the baby was five days old, Ajanupu told her sister that it was time to put alligator pepper in her mouth so that her tongue will be free. It this was not done, Ajanupu said, the baby might be deaf and dumb. - Когда девочке было 5 дней, Аджанупу сказала сестре что пора положить ей в рот крокодилий перец, чтобы освободить ей язык. Если это не будет сделано, ребенок может быть глухонемым (Efuru 1966: 3).

Когда у представителей народа йоруба рождается ребенок, ему дают немного этой специи (atare) в рамках праздника наречения имени малыша (naming cere- 
mony). Этот ингредиент является традиционным на разных праздниках. У народа игбо крокодилий перец и орех кола подаются гостям. Представляет интерес вторичная номинация названий этого продукта. С лексемой pepper находим следующие фразеологизмы:

to pepper somebody - разозлить кого-либо:

He is doing this to pepper me. - Он делает это, чтобы разозлить меня (Atta 2010: 57);

to smell pepper — получить неприятности;

to show pepper - наказать, разобраться с кем-то:

I will show you pepper today. — Я тебе сегодня покажу! (Igboanusi 2002: 251).

Приведем еще несколько примеров фразеологизмов и пословиц, компонентами которых выступают наименования еды или напитков:

coconut-head - тугодум:

You have a coconut-head. - У тебя голова как кокос (ты тупой) (Igboanusi, 2002: 79);

to bring palm wine (пить пальмовое вино) - свататься;

wine-carrying ceremony - церемония сватовства, когда родня жениха приходит с вином и другими подарками для знакомства с родителями невесты.

Лексема bread-fruit (хлебное дерево) употребляется в нигерийской пословице, которая отражает картину мира и древнюю устную традицию народов страны:

The bread-fruit which chooses to fall on the day of festivity has not fallen early enough - всему свое время.

Благодаря пословицам, патриархальная община продолжала вековые традиции и порядки, способствуя формированию нормы отношений, воспитывая идеального африканца. Такие изречения выражают законченную мысль об окружающей действительности и являются истиной в глазах представителей данной лингвокультуры.

В нашем материале мы обратили внимание на то, что в нигерийском варианте английского языка реалии окружающего мира, имена нигерийской флоры являются основаниями для сравнений и представляют элемент особого взгляда на действительность, который фиксируется языковой картиной мира (ЯКМ) нигерийцев:

(15) The girl swung her hips like a ripe mango on a tree. - Девушка покачивала бедрами подобно тому, как качается созревшее манго на дереве (Shoneyin 2010: 98).

(16) When she opens her mouth English begins to pour from it like heated palm oil. Когда она открывает рот, английский язык начинает литься из него как разогретое пальмовое масло (Shoneyin 2010: 4).

(17) "She is very fair, she looks mixed, and the thing is that she is not even pretty, she has a face like an overripe yellow pawpaw". - Она очень светлокожая, она выглядит как полукровка, и дело в том, что она не просто симпатичная, ее лицо выглядит как спелая желтая азимина (Adichie 2009: 10).

Уточним, что азимина (paw paw) представляет собой двудольные цветковые растения, дающие плоды, похожие на манго. Нигерийцы часто варят листья дерева 
и используют их в лечении простуды и малярии. Еще один компаративный оборот из нигерийского художественного дискурса отражает национальную картину мира:

(18) Even though she must have been nearing sixty, Segun's mother's skin glistened like the flesh of a pawpaw sliced open. - Несмотря на то, что ей было к шестидесяти, кожа у матери Сегуна блестела как мякоть разрезанной азимины (Shoneyin 2010: 178).

Для нигерийской языковой картины мира характерно приписывание растениям свойств и признаков человека, в традиционном народном восприятии они относятся к разряду живой природы. Пример находим в произведении нигерийской писательницы Ч. Адичи:

(19) I've seen him talking to the kroton plant. - Я видел, как он разговаривал с кротоном (Adichie: 2006). Кротон (kroton plant) — тропическое и субтропическое растение, распространенное в Нигерии.

Лексема cashew (cashew tree - дерево, плод которого является распространенным продуктом питания в Нигерии) встречается как метафора, которая представляет человека через растительную номинацию, что отражает индивидуально авторскую картину мира:

(20) She was walking across the yard towards him. She had only a wrapper tied around her chest, and as she walked, he imagined that she was a yellow cashew, shapely and ripe. - Она шла через двор к нему. На ней была только юбка, завязанная на груди, и пока она шла он представлял, что своими формами она похожа на желтый зрелый плод кешью (Adichie 2006: 24).

Лексема cassava (важное пищевое корнеплодное тропическое растение, которое широко распространенная в Нигерии) также встречается в произведениях нигерийских писателей в сравнительных оборотах:

(21) The ride to his village was mostly silent. As they drove past some farms with rows and rows of corn and cassava like a neatly plaited hairstyle, Master said, 'See?' По дороге в деревню они в основном молчали. - Когда они проезжали мимо ферм с многочисленными посадками кукурузы и маниока, похожими на аккуратно заплетенные косички, Мастер спросил: «Видишь?». (Adichie 2006: 88).

(22) I was compensation for the failed crops. I was just like the tubers of cassava in the basket. - Я была компенсацией за пропавший урожай. Я была как клубни маниока в корзине (Shoneyin 2010: 82).

Таким образом, реалии окружающего мира, имена африканской флоры становятся основаниями сравнений и представляют элемент своеобразного взгляда на действительность, который фиксирует ЯКМ нигерийцев. Такие сравнения не будут употребляться представителями иной семиосферы. Возникновение образных сравнений объясняется особенностями менталитета нигерийцев, наличием специфических местных реалий и установлением своеобразных ассоциативных связей в сознании нигерийцев.

\section{5. Заключение}

Контактная вариантология английского языка открыла новые области междисциплинарных исследований: социолингвистических, лингвокультурологических, лингвокогнитивных. Английский язык в Нигерии является одним из вариан- 
тов английского языка, который сложился в результате языкового контакта и имеет специфические черты, отражая автохтонную культуру. В статье была рассмотрена гастрономическая лексика нигерийской кухни и ее символизация, в первую очередь в этноспецифических художественных текстах англоязычных писателей Нигерии. Представленный материал показывает, что нигерийское лингвокультурное пространство является самостоятельным образованием и отражает нигерийские доминанты культуры, имманентные им ассоциации и символы. Национальная кухня Нигерии является важным аспектом культурной жизни страны, а ее языковая символика, коммуникативная значимость образуют фрагмент картины мира нигерийцев.

Ближайший предметный мир, к которому относится повседневная кухня, становится основой для образного осмысления мира и важной частью национальной языковой картины мира. Рассмотрение лексики, относящейся к тематической группе «национальная кухня» позволяет сделать вывод, что в нигерийском варианте английского языка новые слова образуются с использованием собственно английского и заимствованного лексического материала из автохтонных языков, в основном йоруба и игбо. Рассмотрение гастрономической терминологии в речи нигерийцев существенно обогащает лингвокультурологическое представление о формах существования английского языка, а также показывает универсальные процессы использования общеупотребительных, близких повседневной жизни гастрономических лексем в качестве основы для символизации. Фразеологизмы, связанные с гастрономической лексикой, ярко показывают особенности африканской ментальности. Реалии окружающего мира, зафиксированные лексическими единицами, задают эталоны сравнительных оборотов, пословиц, поговорок, фразеологических единиц, тех элементов специфического взгляда на действительность, который отражен языковой картиной мира нигерийцев. Исследование коммуникативной значимости гастрономической терминологии дает представление о развитии лексики языка, а также о менталитете и языковой картине мире нигерийцев.

(C) А.А. Борисова, Ю.Н. Эбзеева 2019 (c) creative

https://creativecommons.org/licenses/by/4.0/

\section{ФИНАСИРОВАНИЕ И БЛАГОДАРНОСТИ:}

Публикация подготовлена при поддержке Программы РУДН «5-100».

FINANCE AND ACKNOWLEDGEMENTS:

The research done for this work has been funded by 5-100 Project at RUDN.

\section{СПИСОК ЛИТЕРАТУРЫ / REFERENCES}

Алефиренко Н.Ф. Лингвокультурология. Ценностно-смысловое пространство языка. М.: Флинта: Наука, 2016. [Alefirenko, Nikolay F. (2016). Lingvokul'kurologiya. Tsennostnosmyslovoe prostranstvo yazyka (Linguoculturology. Axiological space of the language). Moscow: Flinta: Nauka. (In Russ.)] 
Арутюнова Н.Д. Язык и мир человека. 2-е изд., испр. М.: Языки русской культуры, 1999. [Arutyunova, Nina D. (1990). Yazyk i mir cheloveka (Language and the world of a human). 2 ed. Moscow: Yazyki russkoi kul'tury. (In Russ.)]

Богданова Л.И Оценки и ценности в зеркале словарей русского языка // Вестник Российского университета дружбы народов. Серия: Лингвистика. 2017. Т. 21. № 4. С. 729-748. [Bogdanova, Lyudmila I. (2017). The Reflection of Evaluation in Russian Language Dictionaries. Russian Journal of Linguistics, 21 (4), 729-748] doi 10.22363/2312-9182-2017-21-4-729-748.

Германова Н.Н. Введение в языкознание. Язык в социокультурном контексте. М.: ИПК МГЛУ «Рема», 2017. [Germanova, Natalia N. (2017). Vvedenie v yazykoznanie. Yazyk v sotsiokul'turnom kontekste (Introduction to linguistics. Language in the social and cultural context). Moscow: MGLU "Rema". (In Russ.)]

Зыкова И.В. Коцептосфера культуры и фразеология. М.: Ленанд, 2015. [Zykova, Irina V. (2015). Kotseptosfera kul'tury i frazeologiya (Sphere of concepts and phraseology). Moscow: Lenand. (In Russ.)]

Исмагилова Р.Н. Народы Нигерии. М.: Издательство Восточной литературы. 1963. [Ismagilova, Rosa N. (1963). Narody Nigerii (Peoples of Nigeria). Moscow: Izdatel'stvo Vostochnoi literatury. (In Russ.)]

Исмагилова Р.Н. История Нигерии в новое и новейшее время. М.: Наука, 1981. [Ismagilova, Rosa N. (1981). Istoriya Nigerii v novoe i noveishee vremya (The history of Nigeria in new and contemporary times). Moscow: Nauka. (In Russ.)]

Исмагилова Р.Н. История романных форм в литературах Африки / Институт мировой литературы им. А.М. Горького РАН. М.: Восточ. лит., 2010. [Ismagilova, Rosa N. (2010). Istoriya romannykh form v literaturakh Afriki (The history of novel in African literature) / Institut mirovoi literatury A.M. Gor'kogo RAN. Moscow: Vostochnaya literatura. (In Russ.)]

Карасик В.И. Языковые ключи. М.: Гнозис, 2009. [Karasik, Vladimir I. (2009). Yazykovye klyuchi (Language keys). Moscow: Gnozis. (In Russ.)]

Карасик В.И. Дискурсивное проявление личности // Вестник Российского университета дружбы народов. Серия: Лингвистика. 2016. Т. 20. № 4. С. 56-77 [Karasik, Vladimir I. (2016). Discourse Manifestation of Personality. Russian Journal of Linguistics, 20 (4), 56-77. (In Russ.)]

Кочакова Н.Б. Традиционные культуры народов Нигерии. М.: ИАфр. РАН, 2008. [Kochakova, Natalia B. (2008). Traditsionnye kul'tury narodov Nigerii (Traditional cultures of Nigerian peoples). Moscow: IAfR. RAN. (In Russ.)]

Лаптухин В.В. Пять тысяч километров по Нигерии. М.: Мысль, 1975. [Laptukhin, Viktor V. (1975). Pyat' tysyach kilometrov po Nigerii (Five thousand kilometers from Nigeria). Moscow: Mysl'. (In Russ.)]

Маслова В.А., Пименова М.В. Коды лингвокультуры. М.: Флинта: Наука, 2016. [Maslova, Valentina A., Pimenova, Marina V. (2016). Kody lingvokul'tury (Linguocultural codes). Moscow: Flinta: Nauka. (In Russ.)]

Маслова В.А. Введение в когнитивную лингвистику. М.: Флинта: Наука, 2017. [Maslova, Valentina A. (2017). Vvedenie v kognitivnuyu lingvistiku (Introduction to cognitive linguistics). Moscow: Flinta: Nauka. (In Russ.)]

Мечковская Н.Б. Общее языкознание. Структурная и социальная типология языков. М.: Флинта: Наука, 2009. [Mechkovskaya, Nina B. (2009). Obshchee yazykoznanie. Strukturnaya i sotsial'naya tipologiya yazykov (General linguistics. Structural and social typology of languages). Moscow: Flinta: Nauka. (In Russ.)]

Найденова Н.С. Лингвистический анализ этноспецифического художественного текста. М.: Флинта: Наука, 2014. [Naidenova, Natalia S. (2014). Lingvisticheskii analiz ehtnospetsifi- 
cheskogo khudozhestvennogo teksta (Linguistic analysis of an ethnospecific literature). Moscow: Flinta: Nauka. (In Russ.)]

Нигерия. Справочно-монографическое издание / отв. редакторы И.Г. Большов, Т.С. Денисова. М.: ИАфр РАН, 2013. [Bolshov, Igor G., Denisova, Tatiana S. (eds.) (2013). Nigeriya. Spravochno-monograficheskoe izdanie (Nigeria. Reference book). Moscow: IAfr RAN. (In Russ.)]

Прошина 3.Г. Контактная вариантология английского языка. Проблемы теории. [Proshina, Zoya G. (2017). Kontaktnaya variantologiya angliiskogo yazyka. Problemy teorii. World English Paradigm (World Englishes Paradigm. The problems of theory). Moscow: Flinta: Nauka. (In Russ.)]

Сапрыкина О.А., Найденова Н.С. Романские языки в Тропической Африке и постколониальный художественный дискурс. М.: Инфра-М, 2017. [Saprykina, Olga A., Naidenova, Natalia S. (2017). Romanskie yazyki v Tropicheskoi Afrike i postkolonial'nyi khudozhestvennyi diskurs (Roman languages in Sub-Saharan Africa and post-colonial discourse). Moscow: Infra-M. (In Russ.)]

Чудинов А.П. Национальная ментальность и соответствующие ей метафорические модели. Landau: Verlag Empirische Padagogok, 2004. P. 19-30. [Chudinov, Anatoly P. (2004). National mindset and its metaphoric models. Landau: Verlag Empirische Padagogok, 19-30. (In Russ.)]

Ajani, Timothy T. (2007). Is there indeed a Nigerian English? Journal of humanities and social sciences, 1 (1).

Bamgbose, Ayo. (1998). Torn between the norms: innovations. World Englishes, 17 (1), 1-17.

Banjo, Ayo. (1995). On codifying Nigerian English: Research so far. New Englishes: A West African Perspective. Ibadan: Mosuro Publishers, 203-231.

Crystal, David A. (1997). English as a Global Language. Cambridge: Cambridge University Press.

Crystal, David A. (2006). How Language Works. Pinguin Books Ltd.

Firth, John Rupert. (1956). Descriptive linguistics and the study of English. Selected papers of J.R. Firth, 1952-1959 / Ed. by F.R. Palmer. Bloomington: Indiana University Press, 96-113. Reprint: World Englishes: Critical Concepts in Linguistics / Ed. by K. Bolton and B. Kachru. (2006). Vol. 3. London/New York: Routledge, 203-217.

Gladkova, Anna and Larina, Tatiana (2018). Anna Wierzbicka, Words and the World. Russian Journal of Linguistics, 22 (3), 499-520. doi: 10.22363/2312-9182-2018-22-3-499-520.

Gladkova, Anna and Larina, Tatiana (2018b). Anna Wierzbicka, Language, Culture and Communication. Russian Journal of Linguistics, 22 (4), 717-748. DOI: 10.22363/2312-9182-201822-4-717-748.

Goddard, Cliff and Anna Wierzbicka. (2014). Words and Meanings: Lexical Semantics Across Domains, Languages, and Cultures. Oxford: Oxford University Press.

Kachru, Braj (2006). World Englishes and Culture Wars. The Handbook of World Englishes. London, 450.

Kecskes, Istvan (2014). Intercultural Pragmatics. Oxford: Oxford University Press.

Larina, Tatiana V., Ozyumenko, Vladimir I., Kurteš, Svetlana. (2017). I-identity vs we-identity in language and discourse: Anglo-Slavonic perspectives. Lodz Papers in Pragmatics, 13 (1), $195-215$.

Schnurr, Stephanie, Zayts, Olga (2017). Language and Culture at Work. Routledge.

Wierzbicka, Anna (2003). Cross-Cultural Pragmatics. $2^{\text {nd }}$ ed. Berlin: Mouton de Gruyter.

Wierzbicka, Anna. (2006). English: Meaning and Culture. Oxford: Oxford University Press.

Wilents, Gay. (1992). Binding Cultures. Black Women Writers in Africa and the Diaspora. Indiana University Press. 


\section{Литературные источники / Literary sources}

Achebe, Chinua. (1958). Things Fall Apart. Oxford: Heinemann.

Adichie, Chimamanda Ngozi. (2004). Purple Hibiscus. London: Fourth Estate.

Adichie, Chimamanda Ngozi. (2006). Half of a Yellow Sun. London: Fourth Estate.

Adichie, Chimamanda Ngozi. (2009). The Thing Around Your Neck. London: Fourth Estate.

Adichie, Chimamanda Ngozi. (2013). Americanah. USA: Knopf.

Atta, Sefi. (2010). Swallow. USA: Interlink Pud Group.

Nwapa, Flora. (1966). Efuru. Oxford: Heinemann.

Okoye, Ifeoma. (1982). Behind the Clouds. UK: Longman.

Shoneyin, Lola. (2010). The Secret Lives of Baba Segi's Wives. London: Serpent's tail.

\section{Словари / Dictionaries}

Awde, N., Wambu, O. (1999). Igbo-English / English-Igbo Dictionary \& Phrasebook. Hippocrene Books, (U.S.) N.Y.

Igboanusi, H.A. (2002). Dictionary of Nigerian English Usage. Ibadan, Nigeria.

Killam, D., Ruth, R. (2000). The Companion to African Literatures. Indiana, James Currey.

Oyeleke, C., Mawadza, A. (2019). Yoruba-English/English-Yoruba Dictionary \& Phrasebook. (U.S.) N.Y. Hippocrene Books Inc.

\section{Article history:}

Received: 13 April 2019

Revised: 01 June 2019

Accepted: 15 June 2019

\section{История статьи:}

Дата поступления в редакцию: 13 апреля 2019

Дата принятия к печати: 15 июня 2019

\section{Bionotes:}

ANNA A. Borisova is a PhD student at RUDN University. Her research interests embrace language and culture, intercultural communication, language contacts and discourse analysis.

Contact information: e-mail: borisova_aa@rudn.ru

YULIA N. EBZEEVA is a PhD, Associate Professor, Chair of Foreign Languages Department, Faculty of Philology, RUDN University. Her research interests embrace lexicology, language and culture; intercultural communication and language contacts.

Contact information: e-mail: ebzeeva_yun@rudn.ru

\section{Сведения об авторах:}

АННА АЛЕКСАНДРОВНА БОРИСОВА - аспирант кафедры иностранных языков филологического факультета РУДН. Сфера научных интересов: язык и культура, межкультурная коммуникация, языковые контакты, дискурс-анализ.

Контактная информация: $\boldsymbol{e}$-mail: borisova_aa@rudn.ru

ЮЛИЯ НИКОЛАЕВНА ЭБЗЕЕВА — кандидат филологических наук, доцент, заведующая кафедрой иностранных языков филологического факультета РУДН. Сфера научных интересов: лексикология, язык и культура, языковые контакты, межкультурная коммуникация.

Контактная информация: e-mail: ebzeeva_yun@rudn.ru 